\title{
Análisis conceptual de posibles reformas a la Ley deArbitraje y Mediación tras más de dos décadas desde su publicación*
}

\author{
Edgar Ulloa Balladares** \\ Javier Jaramillo Troya ${ }^{* * *}$ \\ Recibido/Received: 07/08/2020 \\ Aceptado/Accepted: 30/09/2020
}

Sumario: 1. Introducción. 2. Sobre el método de inicio del procedimiento arbitral. 2.1. Inconvenientes. 2.2. Análisis. 2.2.1. Otorgamiento de potestades jurisdiccionales al director del centro de arbitraje. 2.2.2. Vulneración del derecho a la defensa, por el corto período para contestar la demanda. 2.3. Posibles soluciones. 2.3.1. Procedimiento de notificación de controversia o solicitud de arbitraje. 2.3.2. Extensión del término para la contestación de la demanda. 2.3.3. Eliminación de plazos para la contestación a la demanda y reconvención de la LAM. 3. Sobre las solemnidades exigidas para el convenio arbitral. 3.1. Inconvenientes. 3.2. Posibles soluciones. 4. Sobre la noción de materia arbitrable contenida en el ordenamiento jurídico ecuatoriano. 4.1. Inconvenientes de la noción de transigibilidad en lo privado. 4.1.1. Po-

* Los autores agradecen a María Emilia Flores Suasnavas por su invaluable trabajo y ayuda para la elaboración de este artículo.

** Socio en Pérez Bustamante \& Ponce. Árbitro CAM-USFQ. Secretario Arbitral CAM-CCQ. Profesor de Introducción al Derecho, Análisis Jurídico y Obligaciones en la Pontificia Universidad Católica del Ecuador. Abogado por la Pontificia Universidad Católica del Ecuador. Postgrado en Derecho Procesal por la Universidad Andina Simón Bolívar.

*** Asociado Senior en Pérez Bustamante \& Ponce. Secretario Arbitral CAM-CCQ, AMCHAM CAM y CIAM. Profesor de Arbitraje, Derecho de Daños y Litigación Oral en la Universidad San Francisco de Quito. Abogado por la Universidad San Francisco de Quito. Máster en Derecho por la Escuela de Derecho de la Universidad de Harvard.

E. Ulloa Balladares \& J. Jaramillo Troya, “Análisis conceptual de posibles reformas a la Ley de Arbitraje y Mediación tras más de dos décadas desde su publicación”, Revista Ecuatoriana de Arbitraje, No. 11, 2020, pp. 161-213. 
sibles soluciones sobre la noción de arbitrabilidad en lo privado. 4.2. Inconvenientes de la noción de transigibilidad en lo público. 4.2.1. Posibles soluciones sobre la noción de arbitrabilidad en lo público. 5. Sobre la rigidez del procedimiento arbitral en el ordenamiento jurídico ecuatoriano. 5.1. Inconvenientes. 5.2. Posible solución. 6. Sobre la inadecuación del sistema de causales de recusación de los árbitros previstas en la LAM. 6.1. Inconvenientes. 6.2. Posibles soluciones. 7. Sobre la justicia cautelar. 7.1. Inconvenientes. 7.2. Posible solución. 8. Sobre la incompetencia y falta de motivación como causales de nulidad y el efecto de la nulidad del laudo arbitral. 8.1. Inconvenientes. 8.2. Posibles soluciones. 9. Conclusiones.

Resumen: Tras casi veinte años de vigencia de la Ley de Arbitraje y Mediación, en el presente trabajo se analizan los principales problemas del arbitraje tal como ha sido regulado en el Ecuador. En cada sección, los autores se enfocan en demostrar cómo el entendimiento del arbitraje dentro del ordenamiento ecuatoriano desconoce las características propias de la evolución de esta institución. Así, el artículo contiene una crítica del procedimiento arbitral ecuatoriano, pasando por su método de inicio, las solemnidades del convenio arbitral, la noción de materia arbitrable, la rigidez del proceso, las causales de recusación de los árbitros, la justicia cautelar y las causales de nulidad de laudo. Frente a cada problema, se plantea una o varias propuestas de reforma tendientes a un verdadero reconocimiento del arbitraje como un método alternativo de solución de conflictos con autonomía y vida propia, cada vez más apartado de la rigidez que caracteriza al procedimiento judicial.

Palabras Clave: reformas, procedimiento arbitral, Ley de Arbitraje y Mediación, convenio arbitral, arbitrabilidad, recusación, nulidad. 


\section{Conceptual analysis of possible reforms to the Arbitration and Mediation Law after more than two decades since its publication}

Aвstract: After almost twenty years of the Arbitration and Mediation Law's promulgation, the present work analyzes the main issues of arbitration as it has been regulated in Ecuador. In each section, the authors focus on demonstrating how the arbitration understanding within the Ecuadorian legal system disavows this institution's evolution and features. Thus, the article contains a critique of the Ecuadorian arbitration procedure, including its starting method, the formalities of the arbitration agreement, the notion of arbitrability, the procedure rigidity, the grounds for arbitrators' disqualification, precautionary measures, and the award annulment grounds. For each issue, the authors provide one or several proposals for a reform tending to a true recognition of arbitration as an autonomous alternative dispute resolution method, different from the rigid judicial procedure.

KeYwords: reform, arbitration procedure, Ley de Arbitraje y Mediación, arbitration agreement, arbitrability, disqualification, annulment.

\section{INTRODUCCIÓN}

La Ley de Arbitraje y Mediación (en adelante, LAM), vigente desde el año 1997 con modificaciones en el año 2006, tuvo como base la Ley Modelo sobre Arbitraje Comercial Internacional de la Comisión de las Naciones Unidas para el Comercio Mercantil Internacional (en adelante, Ley Modelo CNUDMI).

Después de más de 20 años de su promulgación, la LAM no ha sido revisada desde una perspectiva conceptual y ha permanecido estancada frente a los cambios y constante 
evolución de las instituciones arbitrales, los principios generales del arbitraje y los cambios tecnológicos en el tráfico comercial. Esto implica, desde nuestro criterio, un sinnúmero de complicaciones que principalmente se generan por el modelo ritualista y judicialista -por referencia a la ley procesal ordinaria- que contiene la LAM.

Entre estas complicaciones se encuentran: (i) el método de inicio del procedimiento arbitral; (ii) las solemnidades exigidas para el convenio arbitral; (iii) la noción de materia arbitrable; (iv) la rigidez del procedimiento y referencia a la norma procesal ordinaria; (v) la inadecuación de las causales de recusación de los árbitros; (vi) la justicia cautelar, y; (vii) el régimen de nulidades.

En el presente trabajo, estos problemas serán analizados y realizaremos ciertas propuestas conceptuales de reforma que, consideramos, pueden ayudar a mejorar el sistema.

\section{Sobre EL MÉtodo DE INICIO DEL PROCEDIMIENTO ARBITRAL}

Actualmente, el procedimiento arbitral en Ecuador inicia con la presentación de la demanda ante el director del centro de arbitraje o los árbitros independientes designados conforme al acuerdo de las partes.

Según el artículo 10 de la LAM, la demanda debe contener:

1. La designación del centro o del árbitro ante quien se la propone.

2. La identificación del actor y la del demandado.

3. Los fundamentos de hecho y de derecho, expuestos con claridad y precisión.

4. La cosa, cantidad o hecho que se exige.

5. La determinación de la cuantía.

6. La designación del lugar en que debe citarse al demandado,y la del lugar donde debe notificarse al actor. 
7. Los demás requisitos que la ley exija para cada caso.

Se deberán, además, cumplir los requisitos señalados en el artículo 68 del Código de Procedimiento Civil. A la demanda se acompañará necesariamente el instrumento en que conste el respectivo convenio arbitral o copia auténtica de éste.

Adicionalmente, se adjuntarán las pruebas y se solicitará la práctica de las diligencias probatorias que justifiquen lo aducido en la demanda ${ }^{1}$.

Posteriormente, la demanda debe ser calificada y emplazada al demandado por el director del centro de arbitraje (en el caso del arbitraje administrado) quien, en este caso, ejerce potestades jurisdiccionales; o por los árbitros independientes (en el caso del arbitraje ad-hoc)². Además, según la LAM, el demandado tiene apenas diez días para contestar la demanda, reconvenir, adjuntar y anunciar pruebas ${ }^{3}$.

\subsection{Inconvenientes}

La postura adoptada por la LAM respecto al método de inicio del procedimiento arbitral presenta algunos inconvenientes: (i) otorgamiento de potestades jurisdiccionales al director del centro de arbitraje que deberían corresponder al tribunal arbitral, y; (ii) la posible vulneración del derecho a la defensa del demandado debido al corto período para la contestación, presentación de pruebas y reconvención previsto en la LAM.

\subsection{Análisis}

Como ya indicamos, vamos a dividir este análisis en dos cuestiones fundamentales:

1. Ley de Arbitraje y Mediación, Artículo 10, RO No. 417, 14/12/2006.

2. Ídem, Artículo 11.

3. Ídem, Artículos 11 y 12. 


\subsubsection{Otorgamiento de potestades jurisdiccionales al director del centro de arbitraje}

La jurisdicción es un poder de administrar justicia que únicamente puede ser ejercido por las personas designadas por la ley ${ }^{4}$. El procedimiento arbitral se compone de una etapa prearbitral y una arbitral propiamente dicha.

La etapa prearbitral, en el arbitraje administrado, es "conducida por los directores de los centros de arbitraje, [quienes ejercen funciones como] la admisión o rechazo de la [demanda arbitral], [y] el traslado y la contestación de la demanda arbitral" 5 . En el caso del arbitraje ad-hoc, estas funciones son ejercidas por el mismo tribunal arbitral al momento de constituirse ${ }^{6}$.

Según el cuarto inciso del artículo 7 del Código Orgánico de la Función Judicial (en adelante, COFJ)", “[1]os árbitros ejercerán funciones jurisdiccionales, de conformidad con la Constitución y la ley" ${ }^{\prime \prime}$. Ciertamente, este cuerpo normativo otorga facultades jurisdiccionales exclusivamente a los árbitros, dejando de lado a los directores de los centros, lo que, desde ya, muestra las complicaciones en torno a las disposiciones que a este respecto establece la LAM como es el caso de la posible responsabilidad civil $^{9}$ e incluso

\footnotetext{
4. N. Ordóñez Rivera, "Responsabilidad de los Centros de Arbitraje en Ecuador", Revista Ecuatoriana de Arbitraje, No. 9, 2017.

5. Corte Constitucional de la República de Colombia, Sentencia SU-600, 18/08/1999, fundamento 6, en N. Ordóñez Rivera, N. 4.

6. N. ORdóÑEZ Rivera, N. 4.

7. Cabe anotar que, desde nuestra perspectiva, el arbitraje no debería estar regulado por un cuerpo normativo que regula a la Función Judicial, justamente por su independencia conceptual como método "alternativo" de resolución de disputas.

8. Código Orgánico de la Función Judicial, Artículo 7, RO(S) No. 544, 09/03/2009.

9. El artículo 18 de la LAM establece, de manera preliminar la responsabilidad civil de los árbitros. Ley de Arbitraje y Mediación, N. 1, Artículo 18.

"Art. 18.- Aceptado por los árbitros el cargo de tales, éstos tienen la obligación irrestricta de cumplir las funciones que la presente Ley les asigna, debiendo responder a las partes, en caso de incumplimiento de sus funciones por los daños y perjuicios que su acción u omisión les causare, a menos que se trate de un impedimento justificado".
} 
penal ${ }^{10}$ que podrían tener los directores de los centros en el ejercicio de estas funciones jurisdiccionales.

La relevancia de esto radica en que "las decisiones que se toman en la fase prearbitral tienen una vinculación directa con el arbitraje"11 y "tienen consecuencias importantes en el acceso a la justicia arbitral, pues corresponde al director del centro de arbitramiento, entre otras cosas, decidir sobre la admisibilidad de la solicitud de convocatoria del tribunal de arbitramiento, [lo cual] puede implicar limitaciones al acceso a la administración de justicia"12, facultad que, a nuestro criterio, únicamente debería reconocerse a aquellos llamados a administrar justicia en virtud de la ley y/o el convenio arbitral.

\subsubsection{Vulneración del derecho a la defensa, por el corto período para contestar la demanda}

El problema más importante del método de inicio del procedimiento arbitral según la LAM es, sin duda, la insuficiencia del término de diez días otorgado al demandado para presentar sus excepciones en la contestación de la demanda, recopilar pruebas que sustenten dichas excepciones, e incluso para reconvenir en caso de considerarse oportuno.

$\mathrm{Al}$ respecto, es necesario hacer énfasis en la garantía del debido proceso que reconoce el derecho a la defensa en el

Para un análisis más detallado de esta institución revisar J. JARAMILLO TroyA, "La responsabilidad civil de los árbitros en el Ecuador: hacia la regulación de un ámbito no explorado", Revista Ecuatoriana de Arbitraje, No. 10, 2018.

10. El Código Orgánico Integral Penal establece a los árbitros como posibles sujetos activos del delito de prevaricato. Código Orgánico Integral Penal, Artículo 268, RO(S) No. 180, 10/02/2014. "Art. 268.- Prevaricato de las o los jueces o árbitros.- Las o los miembros de la carrera judicial jurisdiccional; las o los árbitros en derecho que fallen contra ley expresa, en perjuicio de una de las partes; procedan contra ley expresa, haciendo lo que prohíbe o dejando de hacer lo que manda, en la sustanciación de las causas o conozcan causas en las que patrocinaron a una de las partes como abogadas o abogados, procuradoras o procuradores, serán sancionados con pena privativa de libertad de tres a cinco años. Se impondrá además la inhabilitación para el ejercicio de la profesión u oficio por seis meses".

11. Corte Constitucional de la República de Colombia, No. 61, Fundamento 18, en N. OrdóÑEZ RiverA, N. 4.

12. Ibídem. 
numeral 7 del artículo 76 de la Constitución de la República del Ecuador (en adelante, CRE). Según esta norma, el derecho a la defensa incluye el poder "contar con el tiempo y con los medios adecuados para la preparación de [la] defensa"13. Sin embargo, la disposición contenida en el artículo 11 de la LAM genera una potencial vulneración de este derecho de los demandados quienes, en casos de alta complejidad, podrían no tener suficiente tiempo y oportunidad para plantear sus argumentos de hecho y de derecho y recopilar todos los instrumentos probatorios documentales necesarios, dado el corto plazo de diez días establecido en la LAM.

\subsection{Posibles soluciones}

Frente a los problemas planteados, vemos estas alternativas de solución, a saber: (i) la instauración de la notificación o solicitud de arbitraje como forma de inicio del proceso arbitral; (ii) la extensión del término para la contestación de la demanda; o, (iii) la eliminación de plazos para contestación y reconvención de la LAM y remisión a reglamentos de arbitraje. A continuación, las tres propuestas serán revisadas.

\subsubsection{Procedimiento de notificación de controversia o solicitud de arbitraje}

En legislaciones distintas a la ecuatoriana, el arbitraje no inicia con la demanda, sino con una notificación de arbitraje o un requerimiento de someter la controversia a arbitraje. Así lo ha regulado la Ley Modelo CNUDMI:

Artículo 21. Iniciación de las actuaciones arbitrales.

Salvo que las partes hayan convenido otra cosa, las actuaciones arbitrales respecto de una determinada controversia se iniciarán en la fecha en que el demandado

13. Constitución de la República del Ecuador, Artículo 76, RO No. 449, 20/10/2008. 
haya recibido el requerimiento de someter esa controversia a arbitraje $\mathrm{e}^{14}$.

Asimismo, el Reglamento de Arbitraje CNUDMI ha establecido, en su artículo 3:

3. La notificación del arbitraje contendrá la siguiente información:

a) Una petición de que el litigio se someta a arbitraje;

b) El nombre y los datos de contacto de las partes;

c) Una especificación del acuerdo de arbitraje que se invoca;

d) Una especificación de todo contrato $u$ otro instrumento jurídico que haya suscitado o al que se refiera el litigio o, a falta de ese contrato o de otro instrumento jurídico, una breve descripción de la relación controvertida;

e) Una breve descripción de la controversia y, si procede, una indicación de la suma reclamada;

f) La materia u objeto que se demandan;

g) Una propuesta acerca del número de árbitros, el idioma y el lugar del arbitraje, cuando las partes no hayan convenido antes en ello.

4. La notificación del arbitraje podrá contener asimismo:

a) Una propuesta relativa al nombramiento de la autoridad nominadora conforme a lo previsto en el párrafo 1 del artículo 6;

b) Una propuesta relativa al nombramiento del árbitro único conforme a lo previsto en el párrafo 1 del artículo 8;

c) La notificación relativa al nombramiento de un árbitro conforme a lo previsto en el artículo 9 o en el artículo $10^{15}$.

Como puede verse, la notificación o solicitud de arbitraje -que posteriormente es contestada de la misma maneraconstituye la forma en la que el demandante ejecuta y activa el convenio arbitral, señalando, de forma breve, la naturaleza de la controversia a ser sometida al conocimiento de los árbitros.

Este tipo de regulaciones permiten que la etapa prearbitral sea desarrollada sin que se tome alguna decisión de carácter jurisdiccional sustancial, pues tendría como único objetivo que

14. Ley Modelo de la CNUDMI sobre Arbitraje Comercial Internacional (1985 con enmiendas de 2006), Artículo 21.

15. Reglamento de Arbitraje de la CNUDMI (revisado en 2010), Artículo 3. 
las partes involucradas conozcan que existe una controversia sometida a arbitraje y que se nombren los árbitros. No vemos problema ni conflicto en que el director del centro de arbitraje maneje esta etapa bajo estos límites. Es decir, se deja de lado la intervención de los directores del centro en actividades de orden jurisdiccional, limitándola a funciones de mero trámite previas a la constitución del tribunal arbitral.

Tras la solicitud de arbitraje -y su contestación- se procede a constituir el tribunal arbitral que posteriormente conocerá la controversia. Durante el tiempo que transcurre entre la notificación de la solicitud y la designación de los árbitros, ambas partes pueden hacerse una idea del objeto sobre el que versará el procedimiento arbitral y pueden preparar de mejor manera sus respectivos actos de proposición y materiales probatorios.

Posteriormente, el tribunal arbitral constituido, tras escuchar a las partes ${ }^{16}$, establecerá un calendario procesal en el que, acorde a la complejidad de la disputa, señalará plazos razonables para que ambas partes presenten sus memoriales de demanda/contestación a la reconvención y contestación a la demanda/reconvención y, de considerarlo apropiado para la disputa, memoriales de réplica y dúplica.

16. Véase, por ejemplo, el Reglamento de Arbitraje de la CNUDMI (revisado en 2010).

"Artículo 17.1. Con sujeción a lo dispuesto en el presente Reglamento, el tribunal arbitral podrá dirigir el arbitraje del modo que considere apropiado, siempre que se trate a las partes con igualdad y que en una etapa apropriada del procedimiento se dé a cada una de las partes una oportunidad razonable de hacer valer sus derechos. En el ejercicio de su discrecionalidad, el tribunal arbitral dirigirá las actuaciones con miras a evitar demoras y gastos innecesarios y a llegar a una solución justa y eficaz del litigio entre las partes. 2. El tribunal arbitral, en cuanto esté en condiciones de hacerlo tras su constitución y después de invitar a las partes a expresar sus opiniones, fijará el calendario provisional del arbitraje. El tribunal arbitral podrá, en todo momento, tras invitar a las partes a expresar su parecer, prorrogar o abreviar cualquier plazo establecido en el presente Reglamento o concertado por las partes (énfasis añadido)".

Véase, también, el artículo 24 del Reglamento de Arbitraje de la CCI que establece la figura de la conferencia sobre la conducción del procedimiento y calendario procesal y señala en el número 2. "Durante o después de dicha conferencia, el tribunal arbitral deberá establecer el calendario procesal que pretenda seguir en la conducción del arbitraje. El calendario procesal y cualquier modificación del mismo deberán ser comunicados a la Corte y a las partes (énfasis añadido)". 


\subsubsection{Extensión del término para la contestación de la demanda}

Otra opción frente a este problema es la extensión del término para presentar la contestación de la demanda. Al respecto, parece razonable fijar un término de treinta días similar al previsto para la contestación a la demanda en el caso de los procedimientos judiciales ordinarios ${ }^{17}$. De hecho, existe actualmente una propuesta de reforma a la $\mathrm{LAM}^{18}$ que sugiere un término de 20 días para la contestación a la demanda.

Este término parece mucho más razonable que el insuficiente término de diez días que contiene la LAM en la actualidad. Sin embargo, el problema de esta postura es que no atiende a la naturaleza específica de cada controversia sometida a arbitraje, de la cual se podría desprender la necesidad de un término mayor o menor para presentar la contestación a la demanda, la reconvención y sus respectivas pruebas.

Frente a esto, se podría pensar en una disposición similar a la contenida en el artículo 25 del Reglamento de Arbitraje de la CNUDMI que brida cierta flexibilidad en torno a los plazos para presentación de escritos, estableciendo:

[1]os plazos fijados por el tribunal arbitral para la comunicación de los escritos (incluidos los escritos de demanda y de contestación) no deberán exceder de 45 días. Sin embargo, el tribunal arbitral podrá prorrogar los plazos si estima que se justifica la prórroga ${ }^{19}$.

17. Código Orgánico General de Procesos, Artículo 291, RO (S) No. 506, 22/05/2015.

18. Proyecto de Ley Reformatoria de la Ley de Arbitraje y Mediación número 384549, Artículo 4: "[s]ustitúyase en el artículo 11 la palabra "diez" por la palabra "veinte"”.

19. Reglamento de Arbitraje de la CNUDMI, N. 15, Artículo 25. 


\subsubsection{Eliminación de plazos para la contestación a la demanda y reconvención de la LAM}

Finalmente, esta opción implica la eliminación de plazos para la presentación de la contestación a la demanda, de la reconvención y sus respectivas pruebas del procedimiento contemplado en la LAM. En su lugar, se debería contemplar una remisión de la regulación sobre estos plazos a los reglamentos de los centros de arbitraje a los que las partes sometan su controversia, los que: (i) podrían contener disposiciones precisas al respecto o (ii) podrían otorgar la facultad de fijación de plazos de contestación a los árbitros en atención a la naturaleza específica de la controversia, de conformidad con un calendario procesal adecuado al conflicto sometido a su conocimiento.

Cabe anotar que, en casos de arbitraje ad-hoc, las partes podrán optar por regular expresamente esta situación, o, por el contrario, remitirse a un reglamento de arbitraje ad-hoc como es el caso del Reglamento de Arbitraje de la CNUDMI, que brinda a los árbitros la facultad de, previa consulta con las partes, fijar el procedimiento y los plazos acorde al caso.

\section{Sobre las SOlEMNIDAdES EXIGIDAS PARA EL CONVENIO ARBITRAL}

La LAM establece un requisito de escrituración para el convenio arbitral:

Art. 5.- El convenio arbitral es el acuerdo escrito en virtud del cual las partes deciden someter a arbitraje todas las controversias o ciertas controversias que hayan surgido o puedan surgir entre ellas respecto de una determinada relación jurídica, contractual o no contractual ${ }^{20}$.

20. Ley de Arbitraje y Mediación, N. 1, Artículo 5. 
Bajo la LAM, este requisito puede cumplirse de cuatro formas: (i) dentro del negocio jurídico al que la controversia se refiera ${ }^{21}$, en cuyo caso el convenio arbitral toma la forma de una cláusula contractual; (ii) fuera del negocio jurídico principal, en cuyo caso el convenio arbitral debe contener los nombres de las partes y "la determinación inequívoca del negocio jurídico a que se refiere" ${ }^{22}$; (iii) como un contrato principal, al tratarse de convenios arbitrales sobre indemnizaciones extracontractuales, en cuyo caso debe referirse a los hechos específicos de la controversia ${ }^{23}$; y, (iv) como resultado de un intercambio de cartas (convenio arbitral epistolar) o "cualquier otro medio de comunicación escrito que deje constancia documental de la voluntad de las partes de someterse al arbitraje" ${ }^{24}$.

\subsection{Inconvenientes}

Por la redacción de la LAM anteriormente descrita, existen opiniones divergentes sobre la naturaleza de la formalidad en torno a que el convenio arbitral se encuentre reducido a escrito.

En opinión de Ponce Martínez, el convenio arbitral es un contrato solemne ${ }^{25} \mathrm{y}$, por lo mismo, la escrituración es una exigencia ad solemnitatem. Por lo tanto, en ausencia del requisito de escrituración, el convenio arbitral no existe o es nulo. Sin embargo, para otros autores, como SALCEDO VERDUGA, el requerimiento de escrituración contenido en la LAM constituye una formalidad ad probationem y no ad solemnitatem: "[...] en realidad, la exigencia de la forma escrita no es otra

21. Ídem.

22. Ídem.

23. Ídem.

24. Ídem, Artículo 6.

25. A. Ponce Martínez, Notas sobre la cláusula compromisoria y sus efectos en la legislación ecuatoriana, 2011. 
cosa que el medio de prueba que acredita que se ha otorgado el convenio arbitral" ${ }^{26}$.

Ponce Martínez, además, resalta que "el acuerdo arbitral puede constar también en comunicaciones electrónicas cursadas entre las partes, tal como lo establece el artículo 46 de la Ley de Comercio Electrónico, Firmas y Mensajes de Datos, puesto que basta comunicación escrita para que el acuerdo de arbitraje se perfeccione" ${ }^{27}$.

Para nosotros, es claro que al referirse a "cualquier otro medio de comunicación escrito que deje constancia documental de la voluntad de las partes de someterse al arbitraje (énfasis añadido)" la LAM se alinea con la naturaleza ad probationem del requisito de escrituración, que busca, primordialmente, que el tribunal arbitral cuente con una constancia escrita a la que pueda referirse para analizar la validez y eficacia del convenio arbitral. No obstante, ninguna de las posturas queda clara en el ordenamiento jurídico ecuatoriano. En realidad, de la lectura de la LAM no se puede concluir la naturaleza del requisito de escrituración establecido en el artículo $5 \mathrm{y}$, consecuentemente, ante la falta de regulación de las consecuencias de su incumplimiento, la norma nacional se constituye en completamente obsoleta y anacrónica.

\subsection{Posibles soluciones}

La primera solución ante el anacronismo de la disposición de los artículos 5 y 6 de la LAM es una adaptación sistemática del ordenamiento jurídico a lo prescrito en la Convención sobre Reconocimiento y Ejecución de Sentencias Arbitrales Extranjeras (en adelante, Convención de Nueva York), cuyo artículo 2 establece:

26. E. Salcedo Verduga, El Arbitraje: Justicia Alternativa, Distrilib, 2007, p. 111, en A. Ponce Martínez, ibídem.

27. A. Ponce Martínez, N. 25. 
1. Cada uno de los Estados Contratantes reconocerá el acuerdo por escrito conforme al cual las partes se obliguen a someter a arbitraje todas las diferencias o ciertas diferencias que hayan surgido o puedan surgir entre ellas respecto a una determinada relación jurídica, contractual o no contractual, concerniente a un asunto que pueda ser resuelto por arbitraje.

2. La expresión "acuerdo por escrito" denotará una cláusula compromisoria incluida en un contrato o un compromiso, firmados por las partes o contenidos en un canje de cartas o telegramas ${ }^{28}$.

Parecería ser que la Convención de Nueva York contiene una disposición igual a la de la LAM. Sin embargo, la nota interpretativa de la CNUDMI sobre el artículo 2 de la Convención aclara que si bien los acuerdos en arbitraje deben constar por escrito, otras formas no constantes en la Convención también satisfacen el requisito de escrituración ${ }^{29}$. Es justamente a esta recomendación a la que nos referimos al sugerir una adaptación sistemática del texto de los artículos 5 y 6 de la LAM respecto de la Convención de Nueva York.

La segunda propuesta, preferible por arrojar mayor claridad sobre el requisito de escrituración del convenio arbitral, es la adopción de cualquiera de las dos opciones contempladas en la Ley Modelo de la CNUDMI sobre

28. Traducción libre. Convención sobre Reconocimiento y Ejecución de Sentencias Arbitrales Extranjeras (1958), Artículo 2.

"1. Cada Estado parte reconocerá los acuerdos por escrito bajo los cuales las partes acuerdan someter a arbitraje todas las controversias o ciertas controversias que han surgido o pudieren surgir entre ellas respecto a una relación jurídica definida, contractual o no, sobre materias susceptibles de ser resueltas vía arbitraje. 2. El término "acuerdo por escrito" incluirá una cláusula arbitral contenida en un contrato o un convenio arbitral, firmado por las partes o contenido en un intercambio de cartas o telegramas." Texto original: "1. Each Contracting State shall recognize an agreement in writing under which the parties undertake to submit to arbitration all or any differences which have arisen or which may arise between them in respect of a defined legal relationship, whether contractual or not, concerning a subject matter capable of settlement by arbitration. 2. The term "agreement in writing" shall include an arbitral clause in a contract or an arbitration agreement, signed by the parties or contained in an exchange of letters or telegrams."

29. Convención de las Naciones Unidas para el Comercio Mercantil Internacional (2006), Recomendación $\mathrm{A} / 6 / 17$. 
Arbitraje Comercial Internacional (2006), que eliminan como tal el requisito de escrituración, o, dejan clara su naturaleza como formalidad ad probationem.

\section{La primera establece que}

3) Se entenderá que el acuerdo de arbitraje es escrito cuando quede constancia de su contenido en cualquier forma, ya sea que el acuerdo de arbitraje o contrato se haya concertado verbalmente, mediante la ejecución de ciertos actos o por cualquier otro medio ${ }^{30}$.

La segunda opción, reconociendo la evolución del tránsito comercial y el estado actual del arbitraje, no contiene disposición alguna sobre la forma del convenio arbitral. Así, prescribe:

Artículo 7. Definición del acuerdo de arbitraje (Aprobado por la Comisión en su $39^{\circ}$ período de sesiones, celebrado en 2006) El "acuerdo de arbitraje" es un acuerdo por el que las partes deciden someter a arbitraje todas las controversias o ciertas controversias que hayan surgido o puedan surgir entre ellas respecto de una determinada relación jurídica, contractual o no ${ }^{31}$.

Consideramos que reformar las normas de la LAM que refieren, sin mayor contexto, el requisito de escrituración del convenio arbitral mediante la inclusión de disposiciones que tomen en cuenta lo señalado en esta sección ayudaría a poner fin a la discusión infructuosa de la naturaleza de la formalidad de escrituración bajo el ordenamiento jurídico ecuatoriano y, más importante, daría paso para que los convenios arbitrales sean celebrados de cualquier manera, facilitando así el tráfico jurídico.

30. Ley Modelo CNUDMI (2006), Artículo 7, Opción 1.

31. Ídem. Opción 2. 


\section{SOBRE LA NOCIÓN DE MATERIA ARBITRABLE CONTENIDA EN EL ORDENAMIENTO JURÍDICO ECUATORIANO}

La noción de arbitrabilidad objetiva "se refiere a la posibilidad de que el asunto objeto de la controversia sea susceptible de ser sometido a arbitraje: de ser posible arbitrar la disputa, ésta [sic.] podrá ser llevada ante los tribunales arbitrales $[\ldots]^{\prime \prime 32}$.

El ordenamiento jurídico ecuatoriano toma la noción de transigibilidad como criterio de arbitrabilidad objetiva.

Así, el artículo 190 de la CRE "reconoce [al] arbitraje [...], [que] se [aplicará] con sujeción a la ley, en materias en las que por su naturaleza se pueda transigir" ${ }^{\prime \prime}$.

Concordantemente, el artículo 1 de la LAM prescribe:

Art. 1.- El sistema arbitral es un mecanismo alternativo de solución de conflictos al cual las partes pueden someter de mutuo acuerdo, las controversias susceptibles de transacción, existentes o futuras para que sean resueltas por los tribunales de arbitraje administrado o por árbitros independientes que se conformaren para conocer dichas controversias ${ }^{34}$.

Para tratar el tema de la arbitrabilidad en razón de la materia, es importante distinguir entre la noción de arbitrabilidad en lo privado y en lo público, pues parten de lógicas distintas, sin perjuicio de que, como se verá, la solución propuesta es abandonar la noción de transigibilidad como criterio de arbitrabilidad objetiva.

32. M. JimÉnez \& A. SAldarriaga, “Arbitrabilidad, inversión e ilegalidad”, Revista Ecuatoriana de Arbitraje, No. 2, 2010.

33. Constitución de la República del Ecuador, N. 13, Artículo 190.

34. Ley de Arbitraje y Mediación, N. 1, Artículo 1. 


\subsection{Inconvenientes de la noción de transigibilidad en lo privado}

Para analizar el problema que ocasiona esta asimilación, es importante, primero, entender la noción de transigibilidad, que, aunque sea redundante, es la característica de todo aquello susceptible de transacción.

El Código Civil define a la transacción como "un contrato en que las partes terminan extrajudicialmente un litigio pendiente, o precaven un litigio eventual" ${ }^{\prime 35}$. En este sentido, el arbitraje no puede ser asimilable a la transacción. Si bien mediante ambos se puede poner fin a un litigio pendiente, en la transacción -asimilable a la negociación- al ser un método autocompositivo de resolución de disputas, son las partes las que mediante concesiones mutuas ponen fin a la controversia; mientras que, en el arbitraje, que es un método heterocompositivo de resolución de controversias, un tercero llamado tribunal arbitral pone fin a la controversia sin que exista concesión de ninguna naturaleza por las partes.

Así lo explica Agullar Carvajal para quien en el compromiso de árbitros "se asientan las bases para que [el conflicto] sea resuelto, mientras que en la transacción, mediante las concesiones recíprocas de las partes, se pone fin al asunto" ${ }^{\prime 36}$.

En esta línea, y, más allá de la obvia diferencia entre un contrato de transacción y el arbitraje antes señalada, es importante hacer referencia a la noción de materia transigible.

El artículo 2349 del Código Civil prescribe que "[n]o puede transigir sino la persona capaz de disponer de los objetos

35. Código Civil, Artículo 2348, RO (S) No. 46, 24/06/2005.

36. J. Larrea Holguín, Derecho Civil del Ecuador, Corporación de Estudios y Publicaciones, Tomo XIV, 2002, p. 355, en J. Aguilar AndRAde, "Derecho administrativo y transigibilidad", Revista Ecuatoriana de Arbitraje, No. 6, 2014. 
comprendidos en la transacción" ${ }^{37}$. Así, lo transigible se asimila a las materias de libre disposición por los privados. Por eso, "la transacción opera por medio de concesiones recíprocas que se hacen las partes involucradas en la controversia" ${ }^{38} \mathrm{y}$, como ha manifestado la ex Corte Suprema de Justicia, consiste "en la renuncia que cada contratante hace de lo que cree su derecho a fin de evitar que un fallo judicial le quite todo a uno u otro" ${ }^{\prime 39}$.

La pregunta que surge a continuación es si verdaderamente se requiere que las materias sometidas a arbitraje sean de libre disposición. El inconveniente que nace a partir de la asimilación entre arbitrabilidad y transigibilidad se da debido a que en el arbitraje no existe una verdadera negociación o transacción de derechos, es decir, no existen concesiones recíprocas, sino que se encarga a un tercero imparcial la resolución de la controversia sometida a su conocimiento aplicando el ordenamiento jurídico (en el caso del arbitraje en derecho) y respetando las normas de orden público (incluso en el caso del arbitraje en equidad) y dando la razón en todo o en parte a uno o a otro. Por lo tanto, para someter una controversia a arbitraje no es necesario que la materia sobre la que versa sea de libre disposición o renuncia.

Desde nuestra perspectiva, la arbitrabilidad objetiva es un problema distinto al de la libre disponibilidad sobre la materia. En concreto, al ser el arbitraje un método alternativo y excepcional frente a la justicia ordinaria, el Estado puede tener interés en que, por situaciones de orden o políticas públicas, la resolución de controversias respecto de ciertas materias sea limitada a la justicia ordinaria excluyendo el arbitraje. Deberá el Estado, entonces, dejar sentado de forma expresa y detallada, mediante ley, la inarbitrabilidad de esas materias, como es el caso, por ejemplo, del

37. Código Civil, N. 35, Artículo 2349.

38. J. Aguilar Andrade, N. 36.

39. Corte Suprema de Justicia, Sentencia de tercera instancia, Gaceta Judicial, Serie XV, No. 14, 30/07/1992, p. 4135. 
artículo 20(2) de la Ley Orgánica de Incentivos para Asociaciones Publico Privadas que, aunque de manera poco técnica, elimina la posibilidad de pactar arbitraje en "asuntos tributarios".

En todo caso, al menos desde la perspectiva de la casuística, es bastante común que los árbitros conozcan materias no transigibles, como lo es por ejemplo la nulidad de negocios jurídicos; y lo hacen justamente porque las partes les han otorgado esa capacidad.

\subsubsection{Posibles soluciones sobre la noción de arbitrabilidad en lo privado}

Una posible solución al problema de la asimilación de arbitrabilidad y transigibilidad se encuentra en la adopción en la LAM de la doctrina de PAULSSON, consistente en una presunción en favor de la arbitrabilidad de las controversias ${ }^{40}$. Bajo esta doctrina, cualquier controversia es susceptible de ser sometida a arbitraje "siempre y cuando las partes no interpongan una excepción de inarbitrabilidad"41 y el sometimiento del conflicto a arbitraje no comporte una violación a normas de orden público.

Aplicando esta doctrina al ámbito normativo, sería de utilidad una norma que establezca la arbitrabilidad objetiva como regla general salvo todas aquellas materias que, por ley, sean declaradas inarbitrables.

De esta manera, se da un verdadero respeto de la autonomía de la voluntad de las partes, piedra angular del arbitraje, limitada únicamente por aquello que el ordenamiento y el orden público prohíben.

\footnotetext{
40. J. Paulsson, "Still Through a Glass Darkly", ICC International Court of Arbitration Bulletin: Arbitration in the Next Decade, Special Supplement, 1999, en L. Coronel Larrea e I. NúÑEZ Patiño, "La transigibilidad: un criterio incorrecto de arbitrabilidad", Revista Ecuatoriana de Arbitraje, No. 10, 2019.

41. L. Coronel Larrea e I. NúÑez Patiño, N. 40.
} 


\subsection{Inconvenientes de la noción de transigibilidad en lo público}

Si la noción de transigibilidad era inadecuada en lo privado, resulta inadmisible en lo público, pues el Estado no puede disponer libremente de las potestades que le son atribuidas por ley.

Por el contrario, el Estado se rige por el principio de legalidad. En consecuencia, su capacidad de someter una controversia a arbitraje no es libre, sino que debe contar con una habilitación legal que le permita hacerlo ${ }^{42}$. Si se aplicara el concepto de irrenunciabilidad para limitar el sometimiento de la administración pública a arbitraje se llegaría a la desatinada conclusión de que la administración no puede someter sus controversias a arbitraje bajo circunstancia alguna, lo que, a nuestro criterio, resulta absurdo y contrario a las normas existentes en el ordenamiento jurídico ecuatoriano.

\subsubsection{Posibles soluciones sobre la noción de arbitrabilidad en lo público}

En realidad, al igual que lo establecido anteriormente, la solución al respecto radica en eliminar la noción de transigibilidad como criterio de arbitrabilidad objetiva en los artículos 190 de la CRE y 1 de la LAM; o al menos vía reforma legal interpretar el término transigibilidad para efectos del sometimiento a arbitraje tanto en el ámbito privado como el público.

Por otro lado, respecto de la habilitación para el sometimiento a arbitraje en asuntos en los que intervenga el Estado, ya existe una solución en nuestro ordenamiento por cuanto el artículo 190 de la CRE establece la posibilidad

42. J. Aguilar Andrade, N. 36. 
de que la administración pública someta a arbitraje cualquier controversia contractual al señalar que: "[e]n la contratación pública procederá el arbitraje en derecho, previo pronunciamiento favorable de la Procuraduría General del Estado, conforme a las condiciones establecidas en la ley"43. Esta disposición conduce a la consecuencia lógica de que únicamente estará prohibido hacerlo en los casos en que leyes específicas planteen una excepción.

En ese sentido, concordamos con Aguilar AndRADE cuando explica que "la autorización para que las controversias contractuales se sometan a arbitraje incluye toda controversia, con independencia de que la misma se relacione con actos administrativos de ejecución contractual" ${ }^{44}$.

En conclusión, tanto para el ámbito público como el privado, es necesario plantear una reforma a los artículos 190 de la CRE y 1 de la LAM que elimine la noción de transigibilidad como criterio de arbitrabilidad objetiva o al menos una que matice su alcance.

\section{SOBRE LA RIGIDEZ DEL PROCEDIMIENTO ARBITRAL EN EL ORDENAMIENTO JURÍDICO ECUATORIANO}

Las normas procedimentales en la LAM son elementos naturales del convenio arbitral. Es decir, sus regulaciones se incorporan al convenio arbitral si las partes nada dicen al respecto. Con su sola expresión en el convenio arbitral -elementos accidentales-, las partes pueden modificar el procedimiento establecido en la LAM siempre y cuando el acuerdo no contravenga normas de orden público relacionadas, por ejemplo, con el derecho a la defensa.

43. Constitución de la República, N. 13, Artículo 190.

44. J. Aguilar Andrade, N. 36, p. 262. 
Hasta este punto, el procedimiento arbitral parece bastante flexible. Sin embargo, el problema surge precisamente en ausencia de acuerdo de las partes en cuanto al procedimiento, precisamente por el carácter de midnight clauses $^{45}$ de los acuerdos en arbitraje ${ }^{46}$.

\subsection{Inconvenientes}

La LAM, en realidad, no contiene un procedimiento demasiado riguroso que regule al proceso arbitral. Más allá de las disposiciones generales respecto a la presentación de la demanda, su contestación, reconvención y contestación a la reconvención, mediación obligatoria, designación de árbitros y constitución del tribunal, audiencias de sustanciación y de estrados, nulidad y ejecución de laudos, no contiene en sí misma disposiciones que impongan un procedimiento arbitral como tal.

Es necesario dejar claro que estamos de acuerdo con el enfoque que da la LAM a este tema, pues las normas procedimentales deben quedar a la elección de las partes, sea mediante mención expresa en el convenio arbitral o mediante referencia a reglamentos de arbitraje. Problema aparte resulta que, en el medio ecuatoriano, los centros de arbitraje, lejos de construir reglamentos de arbitraje que regulen al procedimiento arbitral y se adapten constantemente a sus necesidades, se han limitado a crear reglamentos de funcionamiento que dejan de lado las normas de procedimiento antes expuestas enfocándose exclusivamente en temas puramente administrativos.

El problema de la LAM, sin embargo, es la referencia que, sin ningún contexto, hace respecto del procedimiento

45. Esto significa que las cláusulas arbitrales usualmente son las últimas en ser redactadas en un contrato, por lo cual generalmente no son elaboradas de manera minuciosa o detallada.

46. S. Molitoris e I. Welser, "The Scope of Arbitration Clauses Or "All Disputes Arising out of or in Connection with this Contract..."”, Austrian Yearbook on International Arbitration, No. 17, 2012, pp. 19-30. 
hacia las normas de la legislación procesal común. Si bien, tanto el arbitraje como la justicia ordinaria son métodos heterocompositivos de resolución de disputas que pueden mantener rasgos comunes, el primero, al ser alternativo, se funda en principios propios de la institución arbitral.

Debemos dejar claro que, en nuestro criterio, en principio no es incorrecto que la legislación procesal común sea supletoria a la LAM; pero consideramos que debe serlo en un último orden de prelación cuando no pueda aplicarse ningún otro medio que asegure autocontener los principios generales del arbitraje. Es decir, la aplicación de la ley procesal común respecto del arbitraje debe ser de ultima ratio.

Lamentablemente, la LAM no sigue este criterio y hace aplicable el COGEP como norma supletoria directa.

Así, en su artículo 37 la LAM señala:

Art. 37.- En todo lo que no esté previsto en esta Ley, se aplicarán supletoriamente las normas del Código Civil, [Código Orgánico General de Procesos] o Código de Comercio y otras leyes conexas, siempre que se trate, [sic.] de arbitraje en derecho.

Lo anterior se agrava al referirnos al insuficiente alcance del artículo 38 de la LAM que regula las normas de procedimiento. Si bien menciona que las partes podrían pactar las normas de procedimiento, no genera medios para autocontener los principios generales de arbitraje en caso de que las partes no lo hagan, provocando la fuga del procedimiento arbitral hacia las normas procesales comunes. Además de lo anterior, no queda claro si las distintas fuentes están listadas en un orden de prelación puesto que, de ser así, parecería ser que el acuerdo de las partes respecto del procedimiento arbitral no es la fuente principal, lo que resulta absurdo siendo que la voluntad de las partes es la piedra angular de la institución arbitral. 
Al respecto, el artículo 38 de la LAM, señala:

Art. 38.- El arbitraje se sujetará a las normas de procedimiento señaladas en esta Ley, al procedimiento establecido en los centros de arbitraje, al determinado en el convenio arbitral o al que las partes escojan, sin perjuicio de las normas supletorias que sean aplicables.

Como se mencionó, entonces, el problema de estas disposiciones es el alcance que se da a las normas supletorias que podrían ser aplicadas en todos los casos en que la LAM guarda silencio respecto a una regulación procedimental específica. Por ejemplo, al no existir en la LAM norma alguna respecto de la práctica de la prueba documental, nada impediría que un tribunal arbitral obligue a las partes a practicar esta prueba leyendo los pasajes pertinentes del documento como lo establece el artículo 196 del COGEP.

Así, pese a la moderada regulación procedimental de la LAM, esta disposición sobre normas supletorias ha generado una judicialización del procedimiento arbitral, haciéndolo tanto o más formal que uno llevado ante la justicia ordinaria. De esta manera, se desconoce una de las características esenciales del arbitraje: la flexibilidad.

\subsection{Posible solución}

Frente al problema planteado, consideramos importante una reforma que en primer lugar fusione el sentido de las normas establecidas en los artículos 37 y 38 para dejar claro que, si bien la norma procesal común es de supletoria aplicación, lo es solo en los casos en que no sea posible aplicar fuentes autocontenidas del sistema arbitral.

En ese sentido sugerimos la inclusión de una norma que, estableciendo un orden de prelación: (i) deje claro que la fuente de primigenia aplicación es el acuerdo de las partes establecido 
en el convenio arbitral o con posterioridad; (ii) otorgue al tribunal arbitral la facultad para que, en caso de desacuerdo entre las partes e insuficiencia de ley respecto de las normas procesales aplicables, las fije de forma obligatoria respetando el principio de igualdad, y; (iii) haga expresa mención a los principios generales del arbitraje como fuente de aplicación para normas de procedimiento con prioridad frente a la norma procesal común.

Respecto de estas soluciones propuestas, podría seguirse el modelo establecido en la legislación peruana de arbitraje, que en su artículo $34^{47}$ establece:

Artículo 34.- Libertad de regulación de actuaciones. 1. Las partes podrán determinar libremente las reglas a las que se sujeta el tribunal arbitral en sus actuaciones. A falta de acuerdo o de un reglamento arbitral aplicable, el tribunal arbitral decidirá las reglas que considere más apropiadas teniendo en cuenta las circunstancias del caso. 2. El tribunal arbitral deberá tratar a las partes con igualdad y darle a cada una de ellas suficiente oportunidad de hacer valer sus derechos. 3. Si no existe disposición aplicable en las reglas aprobadas por las partes o por el tribunal arbitral, se podrá aplicar de manera supletoria, las normas de este Decreto Legislativo. Si no existe norma aplicable en este Decreto Legislativo, el tribunal arbitral podrá recurrir, según su criterio, a los principios arbitrales así como a los usos y costumbres en materia arbitral [...].

En relación con la segunda solución propuesta, el modelo a seguir puede ser el establecido en el artículo 22(2) del Reglamento de Arbitraje de la Cámara de Comercio Internacional que establece:

[c]on el fin de asegurar la conducción efectiva del caso, el tribunal arbitral, previa consulta a las partes, podrá adoptar las medidas procesales que considere apropiadas, siempre que estas no vulneren ningún acuerdo de las partes.

47. Ley General de Arbitraje de Perú, Artículo 34, 01/09/2008. 
Adicionalmente, y con el fin de facilitar los acuerdos de las partes respecto del procedimiento, nos parece aconsejable seguir el modelo que al respecto ha instauradoel Reglamento de Arbitraje de la Cámara de Comercio Internacional que propone: (i) la celebración de una conferencia para la conducción del procedimiento en la que el tribunal arbitral "consultar[á] a las partes sobre las medidas procesales que podrían ser adoptadas de conformidad con el Artículo 22(2) [...]"48, (ii) la redacción de una acta de misión" en la que se "[fija] con precisión la identidad y representación de las partes, las de los árbitros y el sistema de notificaciones, [...] [determina] con precisión las pretensiones de las partes en la litis, junto con el lugar y el idioma del arbitraje y las normas procesales aplicables al procedimiento $\mathrm{y}$ al fondo $[. . .]^{\prime \prime 50} \mathrm{u}$ otra orden procesal en esta línea; y, (iii) el establecimiento de un calendario procesal ${ }^{51}$ que regirá la conducción del procedimiento arbitral acorde a las necesidades y particularidades de cada caso.

Consideramos que este modelo aseguraría la participación de las partes en el establecimiento de normas procesales, o, en su defecto, el establecimiento de un procedimiento acorde a los principios generales del arbitraje que quedarían plasmados en un documento para posterior referencia de las partes y el tribunal.

Adicionalmente, la fijación de un calendario procesal, además de ayudar a la organización del centro de arbitraje, el tribunal arbitral y las partes, sirve fundamentalmente para estructurar el procedimiento arbitral acorde a las necesidades de cada caso. Por ejemplo, en un caso en el que se avizoren excepciones a la competencia del tribunal arbitral, este, escuchando previamente a las partes, podrá bifurcarlo para

48. Reglamento de Arbitraje de la Cámara de Comercio Internacional (2017), Artículo 24(1).

49. Ibídem, Artículo 23.

50. J. Í. DE Hoyos, "El arbitraje institucional", Arbitraje y mediación: problemas actuales y oportunidades, Lex Nova, 2013.

51. Reglamento de Arbitraje de la Cámara de Comercio Internacional (2017), N. 48, Artículo 24(2). 
escuchar los argumentos y decidir al respecto mediante un laudo interlocutorio.

Por otro lado, y de ser el caso que una de las partes proponga excepciones que por su naturaleza deben, sobre la base del principio de eficiencia, ser conocidas de forma preliminar ${ }^{52}$ a las excepciones de fondo, el tribunal arbitral podrá, previa consulta con las partes, diseñar un proceso en el que se discuta previamente sobre esas excepciones a ser decididas, también, mediante un laudo interlocutorio.

Lo anterior deja en evidencia una nueva reforma que deviene de la naturaleza de las propuestas realizadas, que es la eliminación de la figura de la audiencia de sustanciación establecida en la LAM en consideración a que su celebración no debería ser de obligatorio cumplimiento, especialmente en los casos en los que no se disputa la competencia del tribunal arbitral.

Por otro lado, las demás diligencias que, de acuerdo con la LAM, deben cumplirse en la audiencia de sustanciación bien pueden ser conocidas en otro momento procesal de ser requerido. En ese sentido, si existen objeciones a la admisibilidad de las pruebas solicitadas por las partes, el tribunal arbitral podrá establecer una etapa procesal para, previo a escuchar a las partes, resolver al respecto. Asimismo, ya no sería necesario fijar un término para la práctica de pruebas puesto que el calendario procesal supliría esta necesidad.

\section{Sobre la inAdecuación del Sistema de CAUSAles DE RECUSACIÓN DE LOS ÁRBITROS PREVISTAS EN LA LAM}

La LAM no ha sido ajena al tratamiento de circunstancias que podrían comprometer la independencia e imparcialidad

52. En general denominadas excepciones previas. 
de los árbitros. Por ello, el artículo 21 de la LAM establece como causales de recusación para los árbitros "[...] las previstas en el [COGEP] para los jueces". Además, prohíbe la recusación de los árbitros designados por acuerdo de las partes cuando las causales en que se funde la recusación hayan existido o sido conocidas por las partes al momento de su nombramiento. La resolución de las causas de recusación, según esta norma, corresponderá a distintas personas, dependiendo del caso:

[1]a recusación deberá ser resuelta:

a) En el caso de un tribunal colegiado, por aquellos no comprendidos en la demanda de recusación.

Si estos no se pusieren de acuerdo, la recusación deberá ser resuelta por el director del centro;

b) En el caso de que la recusación recayere sobre todos los árbitros, esta deberá ser resuelta por el director del centro;

c) En el caso de tribunal unipersonal la recusación deberá ser resuelta por el director del centro. Para su reemplazo se procederá en la misma forma establecida en el artículo 16;

d) Para el caso de arbitraje independiente la recusación deberá ser resuelta por los miembros del tribunal que no han sido recusados; $\mathrm{y}$,

e) Si fuere tribunal unipersonal o si la recusación recayere en todos los árbitros, esta deberá ser resuelta por el director del centro de arbitraje más cercano al domicilio del actor.

Pese a la válida intención de regulación de procedimiento que contiene la precitada disposición, no sirve más que para reafirmar el hecho de que, en la práctica, la norma adjetiva de la justicia ordinaria se aplica de modo principal y no supletorio a causa de los múltiples reenvíos - muchas veces descuidadosque hace la LAM, desconociendo de este modo la naturaleza particular del arbitraje.

\subsection{Inconvenientes}

Si bien el modo de resolución de las causales de recusación de los árbitros parece ser adecuado, se debe 
señalar que el reenvío que hace el artículo 21 de la LAM al COGEP respecto de las causales de recusación es, al menos, inadecuado considerando la naturaleza del sistema arbitral, y, especialmente, sus particularidades.

De manera general, el ordenamiento jurídico ecuatoriano equivocadamente ha equiparado a los árbitros con los jueces en muchas disposiciones ${ }^{53}$ sin reparar en las distinciones palpables de su naturaleza. Este ejercicio, en nuestro criterio, no tiene sustento, $y$, por el contrario, genera efectos negativos en su tratamiento jurídico, como es el caso de la institución de la excusa y recusación.

Son muchas las diferencias entre un árbitro y un juez, pero, para efectos del análisis al respecto de la excusa y recusación, son al menos dos las que deben considerarse para determinar los inconvenientes de una norma de reenvío como la del artículo 21 de la LAM, a saber: (i) los árbitros pueden ser escogidos por las partes; y, (ii) los árbitros no dedican, necesariamente, el ejercicio de su profesión de forma exclusiva a esta actividad y pueden -a diferencia de los jueces- realizar otras actividades profesionales como abogados en la práctica privada.

Estas diferencias dejan en evidencia un abanico de posibilidades que pueden influir en la imparcialidad e independencia de un árbitro que, por el contrario, no tendrían lugar en la actividad judicial y quedan fuera de la regulación del artículo 21 de la LAM. Evidentemente, lo anterior, deja claro, aún prima facie, que resulta inadecuado regular a jueces y árbitros de la misma manera en relación con la institución de la excusa y recusación.

53. Código Orgánico de la Función Judicial, RO(S) No. 544, 09/03/2009. Artículo 7: “[1]os árbitros ejercerán funciones jurisdiccionales, de conformidad con la Constitución y la ley" y "[e]1 arbitraje, la mediación y otros medios alternativos de solución de conflictos establecidos por la ley, constituyen una forma de este servicio público". 
Pese a lo anterior, y, a fin de sustentar detalladamente la inconveniencia de una disposición de reenvío como la del artículo 21 de la LAM, analizaremos, en primer lugar, la enumeración de causales que contiene el COGEP que permiten excluir del conocimiento de un proceso a un juez cuyas independencia e imparcialidad han sido cuestionadas, para contrastarlas con la particular naturaleza del arbitraje.

\section{El artículo 22 del COGEP prescribe:}

Art. 22.- Causas de excusa o recusación. Son causas de excusa o recusación de la o del juzgador:

1. Ser parte en el proceso.

2. Ser cónyuge o conviviente en unión de hecho de una de las partes o su defensora o defensor.

3. Ser pariente hasta el cuarto grado de consanguinidad o segundo de afinidad de alguna de las partes, de su representante legal, mandatario, procurador, defensor o de la o del juzgador de quien proviene la resolución que conoce por alguno de los medios de impugnación.

4. Haber conocido o fallado en otra instancia y en el mismo proceso la cuestión que se ventila u otra conexa con ella.

5. Retardar de manera injustificada el despacho de los asuntos sometidos a su competencia. Si se trata de la resolución, se estará a lo dispuesto en el Código Orgánico de la Función Judicial.

6. Haber sido representante legal, mandatario, procurador, defensor, apoderado de alguna de las partes en el proceso actualmente sometida a su conocimiento o haber intervenido en ella como mediador.

7. Haber manifestado opinión o consejo que sea demostrable, sobre el proceso que llega a su conocimiento.

8. Tener o haber tenido ella, él, su cónyuge, conviviente o alguno de sus parientes hasta el cuarto grado de consanguinidad o segundo de afinidad proceso con alguna de las partes. Cuando el proceso haya sido promovido por alguna de las partes, deberá haberlo sido antes de la instancia en que se intenta la recusación.

9. Haber recibido de alguna de las partes derechos, contribuciones, bienes, valores o servicios.

10. Tener con alguna de las partes o sus defensores alguna obligación pendiente. 
11. Tener con alguna de las partes o sus defensores amistad íntima o enemistad manifiesta.

12. Tener interés personal en el proceso por tratarse de sus negocios o de su cónyuge o conviviente, o de sus parientes dentro del cuarto grado de consanguinidad o segundo de afinidad.

Más allá de que algunas causales referidas parecen bastante obvias $(1,2,3,6,7,11$ y 12), existen otras que fueron creadas tomando en cuenta las características privativas de la justicia ordinaria.

Así, la causal 4, "[h]aber conocido o fallado en otra instancia y en el mismo proceso la cuestión que se ventila u otra conexa con ella", no tiene sentido si se piensa, por ejemplo, en controversias que se derivan de ejecuciones contractuales que, por su naturaleza, pueden generar más de una reclamación. Lo más lógico, por el contrario, sería que el árbitro que conoció una controversia referente a la ejecución de un contrato que, por tanto, estaría más familiarizado con las circunstancias que rodean al contrato sea quien resuelva todo lo relativo a ellas. No obstante, esta causal impide que un árbitro conozca nuevas controversias surgidas a partir de la misma cuestión.

Por su parte, la causal 5, "retardar de manera injustificada el despacho de los asuntos sometidos a su competencia", no toma en cuenta que, acorde al artículo 25 de la LAM, los árbitros están sujetos a un término original de ciento cincuenta días prorrogables por ciento cincuenta días más -en los que también deberán resolver cualquier solicitud de las partespara emitir el laudo arbitral, por lo que, al menos prima facie, la causal referida que, ciertamente, tiene como experiencia las demoras excesivas que históricamente tuvo la función judicial en Ecuador, parece no ser aplicable al arbitraje.

Sin embargo, y, más allá de lo anterior, consideramos que el tema de demoras por parte del tribunal arbitral conviene ser 
tratado sobre la base de otros incentivos, como, por ejemplo, la disminución de los honorarios a los que los árbitros tienen derecho ${ }^{54}$-siguiendo el ejemplo de instituciones arbitrales internacionales-, o, en casos extremos, mediante la determinación de responsabilidad de los árbitros ${ }^{55}$.

La causal 8, consistente en tener o haber tenido procesos con alguna de las partes, carece de sentido aun tratándose de la justicia ordinaria. Las controversias en contra del Estado son comunes y los jueces y árbitros no son inmunes a ellas. En estricta aplicación de esta causal, ningún juez o árbitro que haya impugnado un acto administrativo cualquiera o la imposición de una multa de tránsito podría volver a ejercer estas funciones jurisdiccionales si es que una de las partes es el Estado o alguna de sus instituciones. De igual forma, la causal 10 podría excluir a todo árbitro del conocimiento de controversias en contra del Estado si tiene una obligación tributaria exigible pendiente de pago, por ejemplo.

La causal 9, "[h]aber recibido de alguna de las partes: derechos, contribuciones, bienes, valores o servicios", demuestra la inconveniencia de realizar un reenvío tan general al COGEP para la excusa y recusación de árbitros. Este numeral no toma en cuenta que son las partes quienes, además de escoger a los árbitros, pagan sus honorarios, sea de manera indirecta a través de un centro o de forma directa, al tratarse de arbitraje ad-hoc. Ciertamente, la intención de la causal es otra, pero lo anterior demuestra la importancia de tratar a jueces y árbitros de manera distinta para efectos de la excusa y recusación.

54. La nota a las partes y el tribunal arbitral sobre la conducción del arbitraje de conformidad con el Reglamento de Arbitraje CCI de 1 de enero de 2019, en la sección VII . Eficacia en la presentación de los proyectos de laudo a la Corte establece la disminución de honorarios del tribunal arbitral en caso de incumplimiento del plazo de seis meses contados desde el cierre de la instrucción para someter el proyecto de laudo a la corte.

55. J. Jaramillo Troya, N. 9, p. 333. 
Se puede ver, entonces, que existen circunstancias mencionadas en el COGEP como causas de recusación de jueces que no deberían ser aplicadas a los árbitros. Ahora bien, existen otras situaciones que podrían comprometer la independencia e imparcialidad de los árbitros que resolverán la controversia y que no son abordadas por el artículo transcrito ni por otras normas del ordenamiento.

Al respecto, se debe resaltar la dificultad de valorar a priori, sin conocimiento del caso específico, las circunstancias que podrían generar un conflicto de interés en el árbitro. Esto por cuanto, detrás de las causales, no existe un estándar adecuado de razonabilidad, sino que son de inexorable cumplimiento aun si el supuesto de hecho que se configura no compromete de forma alguna la independencia e imparcialidad de los árbitros.

Por ello, los autores nos hemos preguntado si, dada la naturaleza intrínsecamente distinta del arbitraje y la justicia ordinaria, y, con ella, de los árbitros y los jueces, es prudente que el sistema de excusa y recusación sea igual para ambos, esto es, un sistema de causales taxativas preestablecidas.

Consideramos que la respuesta es negativa, especialmente tratándose de los árbitros y la multiplicidad de circunstancias que pueden generar dificultades en cuanto a su imparcialidad e independencia y las dificultades ya referidas en torno a las causales reguladas en el COGEP.

\subsection{Posibles soluciones}

Sobre la base de los inconvenientes antes referidos consideramos que, al respecto, el arbitraje ecuatoriano debería, mediante reforma -sea de la LAM o al menos de los reglamentos de arbitraje de los centros- pasar de un sistema de causales a uno de un estándar objetivo de razonabilidad 
para determinar, tomando en cuenta el caso particular, si existe una circunstancia que cree una duda justificada sobre la imparcialidad o independencia de un árbitro y le impida resolver la controversia.

Al respecto, consideramos, entonces, que el estándar a ser adoptado debería hacer referencia a un tercero razonable en similares circunstancias. En ese sentido, entonces, la circunstancia de potencial conflicto deberá ser analizada sobre la base de si, frente a un tercero razonable en circunstancias similares a la que tienen lugar dentro del proceso arbitral, la circunstancia de posible conflicto genera una duda justificada respecto de la imparcialidad o independencia del árbitro.

Un estándar muy similar ha sido el que las Directrices IBA sobre Conflictos de Intereses en el Arbitraje Internacional 2014 de la International Bar Association (en adelante, Directrices) establecen al señalar:

[s]on consideradas justificadas aquellas dudas por las que una tercera persona con buen juicio y con conocimiento de los hechos y circunstancias relevantes del asunto llegaría a la conclusión de que, probablemente, la decisión del árbitro podría verse influida por factores distintos a los méritos del caso presentados por las partes ${ }^{56}$.

Un enfoque similar es el que toma el Proyecto de Reglamento Modelo de Arbitraje Doméstico Instituto Ecuatoriano de Arbitraje que en relación con las disposiciones aplicables al Tribunal Arbitral en su artículo 957, señala:

2. Al aceptar su designación el árbitro debe suscribir una declaración de aceptación, disponibilidad, imparcialidad e independencia. Los árbitros designados deben dar a conocer por escrito al CAM cualesquiera hechos o circunstancias

56. Directrices IBA sobre Conflictos de Intereses en el Arbitraje Internacional 2014 de la International Bar Association, Norma General 2(c).

57. Proyecto de Reglamento Modelo de Arbitraje Doméstico Instituto Ecuatoriano de Arbitraje, Artículos 9(2) y 9(3). 
susceptibles de poner en duda su independencia, así como cualquier circunstancia que pudiere dar lugar a dudas razonables sobre su imparcialidad, tanto al momento de aceptar la designación como durante el transcurso del proceso. El CAM o el Tribunal Arbitral deberá comunicar por escrito dicha información a las partes y fijar un plazo para que éstas realicen sus comentarios.

3. El árbitro deberá dar a conocer inmediatamente y por escrito, tanto al CAM como a las partes, cualesquiera hechos o circunstancias de naturaleza similar a aquellos referidos en el Artículo 9(2) relativas a su imparcialidad o independencia que pudieren surgir durante el arbitraje.

De este modo, las circunstancias que podrían potencialmente significar una duda justificada sobre la imparcialidad e independencia del árbitro serían abordadas de un modo más bien amplio para considerar situaciones que, a la vista de un tercero razonable, resultarían conflictivas. Así, se abordarían aquellas circunstancias que escapan de la creatividad del legislador al momento de plantearlas como causales preestablecidas $\mathrm{y}$, a la vez, se salvaría a aquellas circunstancias que, a los ojos de las partes, no representan un conflicto de interés.

El estándar antes referido tendría que ser aplicado en dos circunstancias, a saber: (i) para el deber de revelación de los árbitros y su excusa, de ser el caso, y (ii) para la resolución de las solicitudes de recusación.

En cuanto al deber de revelación de los árbitros, y, sobre la base del estándar referido, debe tomarse en cuenta que este no depende de sus propias consideraciones sobre las circunstancias que podrían cuestionar su imparcialidad e independencia, sino de todo aquello que, a los ojos de las partes y hasta de un tercero razonable, podrían poner en duda su capacidad de emitir una decisión con objetividad ${ }^{58}$.

58. J. Alonso Puig, "Los árbitros: selección, recusación y reemplazo". THEMIS-Revista de Derecho, No. 53, 2007, p. 161-166. 
Por otro lado, si bien el deber de revelación de un árbitro inicia al momento de su designación previo a su confirmación o posesión, este debe mantenerse a lo largo de todo el proceso arbitral hasta la emisión del laudo por cuanto su imparcialidad e independencia "debe permanecer [...] durante todo el procedimiento arbitral, incluyendo el período de corrección o interpretación de un laudo final [...] asumiendo que dicho período se conoce o es fácilmente determinable" ${ }^{\prime \prime 5}$. En ese sentido, los árbitros deberán informar cualquier circunstancia ocurrida con posterioridad a su confirmación o posesión que, considerando el estándar referido, podría generar dudas justificadas respecto de su imparcialidad o independencia.

$\mathrm{Al}$ respecto, consideramos que sería importante que la LAM sea reformada para incluir expresamente el deber de revelación. De todas formas, los reglamentos de arbitraje de los distintos centros de arbitraje locales también deberían incluir disposiciones al respecto. Así, en todo caso de duda, en presencia de una norma de esta naturaleza, el árbitro deberá preferir revelar la situación a las partes, las cuales podrán: (i) objetar su presencia en el arbitraje y solicitar la recusación en caso de que no haya excusa voluntaria del árbitro acorde al procedimiento y ante la autoridad establecidos en el artículo 21 dela LAM; o, (ii) decidir continuar con el procedimiento sin objetar la imparcialidad e independencia del árbitro o renunciando expresamente a cualquier circunstancia revelada por el árbitro.

Sin que sea trascendental, pero sí recomendable, para la aplicación del deber de revelación de los árbitros podría tomarse como referencia a las ya mencionadas Directrices que han desarrollado un catálogo no taxativo de circunstancias comunes que podrían considerarse conflictivas respecto de la imparcialidad e independencia de los árbitros con una

59. Directrices IBA sobre Conflictos de Intereses en el Arbitraje Internacional 2014 de la International Bar Association, Nota explicativa a la Norma General 1. 
dinámica de listas que se corresponden a los colores de un semáforo acorde a su nivel de gravedad.

Así, las circunstancias que preliminarmente generarían en cualquier persona una duda razonable sobre la imparcialidad e independencia de un árbitro se encuentran en el listado rojo que, a su vez, se subdivide en el listado renunciable y el no renunciable, siendo el primero el que expone circunstancias que generan dudas razonables sobre la imparcialidad e independencia del árbitro pero consideradas renunciables voluntariamente por las partes y el segundo aquellas el que refiere circunstancias tan graves que no podrían ser renunciadas por las partes de un arbitraje.

Por otro lado, las circunstancias que potencialmente podrían generar conflicto de interés pero que no lo hacen intrínsecamente se consideran en el listado naranja. Cabe anotar que estas circunstancias son renunciables por las partes.

Finalmente, las circunstancias que no constituyen conflicto de interés se encuentran en el listado verde.

Como se refirió anteriormente, las Directrices mencionadas son un cuerpo de soft law que, salvo pacto entre las partes o adopción por un cuerpo normativo, no resultan vinculantes pero sí referenciales y persuasivas.

Consideramos que, en lo relacionado con las listas antes referidas respecto del deber de revelación de los árbitros, parecería importante que no sea una reforma a la LAM la que las imponga sino que esto quede librado a la voluntad de las partes, sea mediante un pacto expreso en el convenio arbitral o mediante el sometimiento a un cuerpo de reglas de arbitraje que las incorporen.

De todas formas, como se mencionó, los árbitros podrán considerarlas para efectos de su deber de revelación, siempre 
sobre la base del estándar objetivo de razonabilidad antes expuesto que se recomienda incluir en la LAM mediante reforma.

Finalmente, el estándar objetivo de razonabilidad antes referido deberá guiar y ser el aplicable en lo relativo a solicitudes de recusación que sean planteadas por las partes en un proceso arbitral. Estas solicitudes, como se mencionó, deberían ser resueltas por la autoridad y acorde al procedimiento establecidos en el artículo 21 de la LAM sobre la base de las consideraciones específicas de cada caso y podrán, de ser oportuno, tomar en cuenta las Directrices o cualquier otro cuerpo normativo similar como soft law para su decisión.

De hecho, decisiones locales $^{60}$ han aplicado, por considerarlas normas referenciales persuasivas, las Directrices para decidir respecto de solicitudes de recusación por falta de imparcialidad o independencia de árbitros.

\section{Sobre la jUSticia CAUTElar}

El artículo 9 de la LAM reconoce a los árbitros la potestad de dictar medidas cautelares:

Art. 9.- Los árbitros podrán dictar medidas cautelares, de acuerdo con las normas del [COGEP] o las que se consideren necesarias para cada caso, para asegurar los bienes materia del proceso o para garantizar el resultado de éste [sic.] [...]

Para la ejecución de las medidas cautelares, los árbitros siempre que las partes así lo estipularen en el convenio arbitral, solicitarán el auxilio de los funcionarios públicos, judiciales, policiales y administrativos que sean necesarios sin tener que recurrir a juez ordinario alguno del lugar donde se encuentren los bienes o donde sea necesario adoptar las medidas.

60. Decisión de Recusación Santiago Cuesta Caputi, Tribunal Arbitral Independiente, Caso Chaparro c. Ecuador, Gaceta Arbitral No. 1 - 2013, 09/08/2011, pp. 336-346. 
Si nada se estableciere en el convenio arbitral acerca de la ejecución de las medidas cautelares, cualquiera de las partes podrá solicitar a los jueces ordinarios que ordenen la ejecución de estas medidas, sujetándose a lo establecido en el párrafo dos (2) y tres (3) de este artículo, sin que esto signifique renuncia al convenio arbitral.

Es así que, contrario a lo que establecen la mayoría de las legislaciones de arbitraje en el mundo, bajo la LAM, los árbitros poseen facultades para dictar medidas cautelares de forma directa apoyándose en las distintas autoridades públicas bajo un sistema abierto, es decir, no taxativo, para proteger la disputa, las partes, el status quo del conflicto, para asegurar el resultado del laudo o para no agravar innecesariamente el conflicto.

A simple vista, parecería que el régimen de justicia cautelar de la LAM no presenta una necesidad de reforma dado su avance al respecto. Sin embargo, las particularidades del sistema arbitral pueden provocar que el objeto principal de la justicia cautelar no se cumpla.

\subsection{Inconvenientes}

Para entender los inconvenientes que el sistema de justicia cautelar en el arbitraje genera, es importante revisar el momento en que las medidas cautelares pueden ser solicitadas.

Como analizamos, la LAM reconoce la facultad de dictar medidas cautelares exclusivamente a los árbitros. Por lo tanto, según la LAM, con la que concordamos conceptualmente en este punto, no sería posible que el director del centro de arbitraje sea quien las dicte antes de la constitución del tribunal arbitral pues esto, además, implicaría que el director del centro de arbitraje tenga jurisdicción para actos distintos a la calificación de la demanda y la citación del demandado, lo cual es inadmisible bajo la legislación ecuatoriana. 
Así, las medidas cautelares en arbitraje únicamente podrían ser dictadas luego de que el tribunal arbitral se encuentre constituido y se haya declarado competente. Esto ocurre recién luego de que la etapa prearbitral ha concluido ${ }^{61}$. En este sentido, desde la demanda -en la que en principio se solicitan las medidas cautelares- hasta que la etapa prearbitral concluya, en la práctica transcurre un tiempo considerable, lo que pone en tela de duda la existencia de una justicia cautelar verdaderamente efectiva ${ }^{62}$.

Por otro lado, no resulta una solución conveniente que los accionantes recurran a la justicia ordinaria para solicitar medidas cautelares en consideración a que el sistema cerrado de las medidas posibles podría colisionar con la naturaleza del arbitraje.

\subsection{Posible solución}

En virtud de lo expuesto, consideramos necesario que las medidas cautelares puedan ser dictadas por un árbitro competente antes de la constitución del tribunal arbitral que conocerá la controversia principal.

Para esto, es importante reconocer en el sistema arbitral ecuatoriano al arbitraje de emergencia, bajo el cual sería posible que un árbitro designado temporalmente, que asume competencia solo prima facie para determinar la procedencia de las medidas cautelares solicitadas, las ordene antes de la constitución del tribunal arbitral a través de un trámite expedito ${ }^{63}$.

\footnotetext{
61. La etapa prearbitral, en nuestro sistema, comprende: presentación de la demanda, citación a la contraparte, contestación de la demanda, reconvención, contestación a la reconvención, mediación obligatoria, designación y posesión de árbitros.

62. H. Escudero Állvarez, F. Jaramillo Intriago, \& A. K. Parra, "El arbitraje de emergencia: ¿Una figura aplicable en el sistema arbitral ecuatoriano?”, Revista Ecuatoriana de Arbitraje, No. 9, 2017.

63. Ibídem.
} 
La figura del arbitraje de emergencia no ha sido bien recibida por el Estado ecuatoriano pese a haber obtenido un resultado favorable en su primera experiencia. Lo anterior, por lo expedito de los plazos y las dificultades de reacción del sector público por los procesos internos que deben cumplirse. Muestra de ello es que en las reformas incluidas por la Ley Orgánica para el Fomento Productivo, Atracción de Inversiones, Generación de Empleo, y Estabilidad y Equilibrio Fiscal al Código Orgánico de la Producción Comercio e Inversiones respecto de arbitraje, se estableció de manera expresa que "[1]as reglas de arbitraje de emergencia no se aplicarán en ningún caso" ${ }^{64}$.

Por lo anterior, debemos aclarar que no consideramos que la figura del arbitraje de emergencia debería ser incluida mediante disposición legal sino, más bien, en los distintos reglamentos de los centros de arbitraje, diseñando un proceso adecuado con vías alternativas para las partes que no consientan en su aplicación.

\section{SOBRE LA INCOMPETENCIA Y FALTA DE MOTIVACIÓN COMO CAUSALES DE NULIDAD Y EL EFECTO DE LA NULIDAD DEL LAUDO ARBITRAL}

El artículo 31 de la LAM establece las causas por las cuales un laudo puede ser susceptible de una acción de nulidad:

Art. 31.- Cualquiera de las partes podrá intentar la acción de nulidad de un laudo arbitral, cuando:

a) No se haya citado legalmente con la demanda y el juicio se ha seguido y terminado en rebeldía. Será preciso que la falta de citación haya impedido que el demandado deduzca sus excepciones o haga valer sus derechos y, además, que el demandado reclame por tal omisión al tiempo de intervenir en la controversia;

64. Ley Orgánica para el Fomento Productivo, Atracción de Inversiones, Generación de Empleo, y Estabilidad y Equilibrio Fiscal, Artículo 37, RO No. 309, 21/08/2018. 
b) No se haya notificado a una de las partes con las providencias del tribunal y este hecho impida o limite el derecho de defensa de la parte;

c) Cuando no se hubiere convocado, no se hubiere notificado la convocatoria, o luego de convocada no se hubiere practicado las pruebas, a pesar de la existencia de hechos que deban justificarse;

d) El laudo se refiera a cuestiones no sometidas al arbitraje o conceda más allá de lo reclamado; o,

e) Cuando se hayan violado los procedimientos previstos por esta Ley o por las partes para designar árbitros o constituir el tribunal arbitral.

La Corte Constitucional, en sentencias de 19 de noviembre de 2019, ha dilucidado dudas que han atacado a la comunidad arbitral por mucho tiempo referentes: (i) a la taxatividad de las causales de nulidad de laudos arbitrales y su alcance, y, (ii) las circunstancias en las que debe agotarse la acción de nulidad previo a plantear una acción extraordinaria de protección (en adelante, AEP), en contraste con aquellas en las que puede accionarse directamente la AEP frente al laudo arbitral.

En las Sentencias No. 31-14-EP/19 y No. 323-13-EP/19, específicamente, la Corte aclaró que el artículo 31 de la LAM tiene carácter numerus clausus y que, por lo tanto, no cabe intentar acciones de nulidad por causales diferentes a las previstas en dicha disposición ${ }^{65}$.

Es importante mencionar en este punto que la causal contenida en el literal d) ha sido interpretada extensivamente por los presidentes de las cortes provinciales en calidad de

65. Corte Constitucional del Ecuador, Sentencia No. 323-13-EP/2019, Caso No. 323-13-EP, 19/11/2019, párr. 31-32, "31. A este respecto, es preciso que la Corte Constitucional efectúe una aclaración, pues la sentencia constitucional No. 302-15-SEP-CC, determinó que existió vulneración de derechos por parte del juzgador de justicia ordinaria dentro de una acción de nulidad de laudo, por considerar que la falta de competencia y de motivación constituyen causales de nulidad que, aunque no están expresamente contempladas en el artículo 31 de la LAM, deben ser analizadas de oficio durante cualquier acción de nulidad. Así, la Sentencia No. 302-15-SEPCC, estableció: [...] 32. Sin embargo, este Organismo se aparta de este criterio por cuanto taxatividad que tienen las causales de la acción de nulidad y que constituyen principio de intervención judicial mínima que precisamente limita injustificada de la justicia ordinaria en el arbitraje (énfasis añadido)". 
jueces de nulidad para cubrir el supuesto de incompetencia del tribunal arbitral.

Frente a esto, y como consecuencia de las decisiones de la Corte Constitucional antes descritas, se estableció de manera clara que la incompetencia del tribunal arbitral ni la falta de motivación son causales contempladas en el artículo 31 de la LAM, dejando claro que dichos supuestos no son accionables por vía de la acción de nulidad, sino exclusivamente mediante una acción extraordinaria de protección ${ }^{66}$.

\subsection{Inconvenientes}

El precedente sentado por la Corte Constitucional, si bien solventa dudas importantes, deja todavía un problema latente que se traduce en que existen dos vías ante dos autoridades distintas para accionar frente a un laudo arbitral. Es cierto que actualmente no existe otra forma distinta a la AEP para revisar las decisiones arbitrales dictadas por tribunales incompetentes o cuyos laudos contengan una falta de motivación, y que es esa la única vía de proteger el derecho de las personas a la defensa y el debido proceso, reconocido en el artículo 76 de la $\mathrm{CRE}^{67}$.

Es nuestro criterio que la situación vigente atenta contra el principio de uniformidad del ordenamiento jurídico, por lo

66. Corte Constitucional del Ecuador, Sentencia No. 31-14-EP/19, Caso No. 0031-14-EP, 19/11/2019, párr. 41 y 50. "41. A diferencia de la garantía jurisdiccional que nos ocupa, la acción de nulidad fue concebida como un medio de impugnación extraordinario por errores inprocedendo en el arbitraje y vicios de extra petita en la decisión, relacionados al debido proceso arbitral y establecidos taxativamente en el artículo 31 de la Ley de Arbitraje y Mediación como causales de nulidad del laudo. La taxatividad de estas causales se fundamenta en las razones que se explicarán a continuación. [...] 50. Considerando lo expuesto, esta Corte no comparte el criterio vertido en la sentencia $N^{\circ}$. 302-15-SEP-CC14, mediante la cual se estableció que el juez que conoce la acción de nulidad del laudo puede resolver sobre causales no previstas en el artículo 31 de la Ley de Arbitraje y Mediación. Según la sentencia referida, dicho juez está al servicio de la satisfacción de los derechos constitucionales en un Estado constitucional de derechos y justicia. Por tanto, se lo facultó para revisar el laudo por cuestiones como: (i) la falta de competencia del tribunal arbitral por la violación del derecho establecido en el literal $k$ ), numeral 7 del artículo 76 de la $C R E$; $y$, (ii) la falta de motivación en el laudo arbitral por la vulneración del derecho previsto en el literal 1), numeral $7 \mathrm{del}$ artículo ibídem (énfasis añadido)".

67. Constitución de la República, N. 13, Artículo 76. 
que una reforma al sistema actual que tome una de las dos vías para todas las causales que sean consideradas resulta primordial. Consideramos que, teniendo en cuenta la práctica local, la alta carga de trabajo de la Corte Constitucional y el mismo hecho de que los presidentes de cortes provinciales actualmente analizan violaciones del proceso arbitral y/o laudo al derecho a la defensa y debido proceso en relación con las causales a), b) y c) del artículo 31 de la LAM, son estos quienes, mediante la acción de nulidad, deberían conocer todas aquellas acciones a ser propuestas frente a laudos arbitrales, lo que permitiría su especialización al respecto, así como la consistencia y predictibilidad de sus decisiones.

Sin embargo, la posible revisión de la competencia de un tribunal arbitral por un órgano judicial no es pacífica. Doctrinariamente, se ha disputado si debiera existir esta revisión o second look a la decisión de competencia del tribunal. La original doctrina alemana del kompetenz-kompetenz sostenía que la decisión sobre la competencia es única y exclusiva del tribunal arbitral por lo que la decisión al respecto no podría ser revisada por el tribunal ordinario ${ }^{68}$. Al respecto, podría sostenerse que la LAM siguió esta tendencia al no incluir a la incompetencia como causal de nulidad del laudo arbitral.

Sin embargo, actualmente, la doctrina alemana del kompetenz-kompetenz aboga en pro de que el tribunal arbitral sea el primero en revisar su competencia, sin perjuicio de que una corte ordinaria lo haga con posterioridad ${ }^{69}$. La Ley Modelo CNUDMI, sobre la que se basó la LAM, ha tomado este último enfoque al reconocer en su artículo 34(b)(i) a la inarbitrabilidad de la materia como causal de anulación del laudo ${ }^{70}$. Cabe recalcar que la ley alemana de arbitraje ha

68. J. BARCELÓ III, "Who Decides the Arbitrators' Jurisdiction? Separability and Competence-Competence in Transnational Perspective", Cornell Law Faculty Publications, p. 1131.

69. Ibídem, p. 1124.

70. Ley Modelo de la CNUDMI sobre Arbitraje Comercial Internacional (1985 con enmiendas de 2006), Artículo 34(b)(i). 
abandonado el modelo original antes descrito optando por adaptarse a la Ley Modelo CNUDMI. Algo similar ocurre con la Convención de Nueva York que, en su artículo (V)(2)(a), reconoce a la inarbitrabilidad de la materia como una causa para denegar la ejecución de un laudo arbitral extranjero. Las legislaciones de Chile y Colombia, que también se han adaptado a la Ley Modelo CNUDMI reconocen a la inarbitrabilidad como causal de incompetencia. La doctrina ecuatoriana ${ }^{71}$ también ha considerado necesaria una reforma al respecto ampliándola a una causal de incompetencia que incluya, además de la arbitrabilidad, la competencia en razón de la persona y voluntad.

Más allá de la autoridad que conozca la acción de nulidad y considerando la importancia de que perfeccione su conocimiento en materia arbitral, creemos que resulta ventajoso incluir una causal de incompetencia en la LAM, no solo porque las tendencias mundiales en arbitraje así lo apuntan, sino porque el ser juzgado por autoridad competente es un derecho reconocido expresamente en el artículo 76 de la $\mathrm{CRE}$, y parece razonable que una decisión de esta importancia pueda ser revisada en caso de que el tribunal arbitral haya errado en su análisis al respecto.

Análisis aparte merece el tema relacionado con la inclusión de la falta de motivación como causal de nulidad del laudo arbitral bajo la LAM. Esto por cuanto, diferente a lo establecido respecto de la causal de incompetencia, el derecho comparado en materia de arbitraje, mayormente, se ha alejado de esta posibilidad, principalmente por miedo a que, en su nombre, se pretenda una revisión del fondo del laudo que, como conocemos, es ajena a la naturaleza de la acción de nulidad. De hecho, la Ley Modelo CNUDMI ni la Convención de Nueva York reconocen causal alguna que apunte a una falta de

71. V. Centeno, A. Morales \& R. Sánchez, "Falta de competencia del Tribunal Arbitral como causal de nulidad del laudo", Revista Ecuatoriana de Arbitraje, No. 9, 2017. 
motivación de la decisión del tribunal arbitral, limitándose en sus respectivos artículos 34(b)(ii) y V(2)(b) al incumplimiento del orden público como causal.

Sin embargo, por ejemplo, el Convenio CIADI, en su artículo 52, establece como causales de anulación de laudos circunstancias en las que "el Tribunal se hubiere extralimitado manifiestamente en sus facultades"72 o "que no se hubieren expresado en el laudo los motivos en que se funde" ${ }^{73}$. Asimismo, el Código de Procedimiento Civil belga establece la falta de motivación como causal de nulidad del laudo ${ }^{74}$. Así también, el Federal Arbitration Act de Estados Unidos establece que se puede anular un laudo cuando los árbitros han excedido sus facultades, "o las han ejercido de forma tan imperfecta que un laudo mutuo, final y definitivo no tuvo lugar"75.

Como puede verse, las normas y legislaciones que han adoptado la falta de motivación o manifiesto exceso de poder como causal de nulidad han sido cautelosas en su redacción, dejando claro que el estándar para alcanzarla es alto y se da en casos realmente excepcionales. Asimismo, las cortes que interpreten esta causal deben ser celosas en su aplicación para evitar que mediante esta causal se pretenda revisar el fondo del laudo.

Es justamente esta la mayor limitante para incluir esta causal puesto que como señala LALIVE:

[p]ero puede no ser fácil trazar la línea entre los motivos de apelación (una revisión del fondo) y un procedimiento de anulación propiamente dicho. Siendo que las partes que se oponen a la anulación rápidamente alegarán, como una especie de inevitable 'Leit-motiv', que el reclamante,

72. Convenio CIADI, Artículo 52(1)(b).

73. Ibídem, Artículo 52(1)(b).

74. Código de Procedimiento Civil de Bélgica, Artículos 1704.2.i-j, en O. Van Der Haegen, "Two recent Belgian cases on the review of motivation of arbitral awards at the annulment and enforcement stages", Kluwer Arbitration Blog, 2012.

75. Federal Arbitration Act, Sección 10(a)(4). 
ya sea estatal o inversor, de hecho está presentando una apelación disfrazada ${ }^{76}$.

Consideramos que, aunque esta problemática puede ser real, más aún cuando jueces de nulidad en el pasado han anulado laudos por estar en desacuerdo con la motivación del tribunal arbitral ${ }^{77}$, esto no debe impedir que la legislación avance en el sentido que debe hacerlo.

Ciertamente, no es un tema pacífico y, aunque los autores se inclinan por negar la posibilidad de incluir la causal de falta de motivación dentro de la LAM, es innegable que el tema será igualmente discutido en sede constitucional por lo que, como se señaló anteriormente, sobre la base del principio de uniformidad, consideramos que es preferible que todas las acciones frente al laudo arbitral se concentren en una sola vía ante una sola autoridad que, a nuestro criterio, deberían ser los presidentes de las cortes provinciales. En ese caso, los autores consideran que la causal, de ser incluida, debe tener un alcance muy limitado y claro para evitar los problemas antes descritos.

Finalmente, el artículo 31 de la LAM omite pronunciarse sobre las consecuencias de la declaratoria de nulidad para cada una de las causales que pueden ser invocadas, lo que genera

76. P. Lalive, "On the Reasoning of International Arbitral Awards", Journal of International Dispute Settlement, Vol. 1, No. 1, 2010, p. 58.

77. Liga Deportiva Universitario de Loja c. Compañia Centro de Radio y Televisión, Cratel S.A.: "En cuanto a la causal de nulidad determinada en el literal d) del artículo 31 de la LAM, es válida cuando "el laudo se refiera a cuestiones no sometidas al arbitraje o conceda más allá de lo reclamado", lo que también abarca cuando el Tribunal Arbitral ha ejercido su labor con exceso o con defecto y no solo cuando hay vicios de incongruencia entre lo reclamado por el actor y las excepciones del demandado. Precisamente, en el caso que nos ocupa, y una vez revisado el laudo, objeto de análisis, el Tribunal Arbitral ha ejercido su labor con defecto, en la medida en que el contenido de la Cláusula Segunda del Contrato de Cesión de Derechos en el numeral 4to., dice: "Las transmisiones televisivas se efectuarán en directo, salvo caso de fuerza mayor o caso fortuito, según definición del Código Civil que lo impida", por tanto, a más de las causales de terminación del contrato establecidas en la Cláusula Décima Quinta del Contrato de Cesión de Derechos, se determina en la citada Cláusula, un motivo más, en virtud del cual podría incumplirse con el Contrato, sin que medie la voluntad de cualquiera de las partes, esto es el caso de fuerza mayor o caso fortuito, lo cual, no ha sido considerado por el Tribunal Arbitral, que estaba en la obligación jurídica de analizar tal figura jurídica, a fin de cumplir con la garantía de la motivación". 
inseguridad jurídica sobre los pasos a seguir -si acaso existenuna vez que un laudo arbitral es declarado nulo.

\subsection{Posibles soluciones}

Frente a los inconvenientes planteados, existen tres posibles soluciones, que deben acogerse de manera conjunta:

(i) Respecto a la incompetencia del tribunal, consideramos importante que el artículo 31 de la LAM incluya como causal de nulidad aquellos casos en los que la materia sobre la que se emitió el laudo es inarbitrable, sin perjuicio de incluir como causal a la incompetencia en razón de la persona y de la voluntad.

(ii) En relación con la falta de motivación, aunque conceptualmente no recomendamos su inclusión, dado su carácter de garantía del debido proceso y derecho a la defensa y su tratamiento bajo el ordenamiento jurídico ecuatoriano, consideramos su incorporación con un alcance limitado.

(iii) Con respecto a las consecuencias de la declaratoria de nulidad, en virtud del principio de preservación del proceso, se recomienda lo siguiente:

(a) Para la primera causal, que incluiría las letras a), b) y c) del actual artículo 31 de la LAM, se sugiere la retrotracción de efectos hasta el momento en que se incurrió en la causal -una suerte de nulidad del proceso-, teniendo que tramitar el procedimiento desde ese punto un nuevo tribunal arbitral.

(b) Para la actual causal d), referente a los vicios de extra y ultra petita se recomienda que el artículo 31 deje claro que, en estos casos, cabe una nulidad parcial del laudo, respecto de aquello otorgado en demasía -en el caso de ultra petita-, de aquello no solicitado y 
otorgado por el tribunal arbitral -en el caso de extra petita-, o resolviendo el nuevo tribunal aquello que se omitió resolver en el laudo -en el caso de citra petita- dejando intacta la parte no incongruente del laudo.

(c) Para la actual causal e), se recomienda la retrotracción de los efectos hasta el momento de designación del tribunal con el fin de que se vuelva a designar a los árbitros de conformidad con el convenio arbitral, el reglamento del centro o la ley.

(d) Para la nueva causal de incompetencia -sea en razón de la materia, persona o voluntad- se recomienda que se declare nulo todo el proceso a fin de que las partes ejerzan su derecho potestativo alternativo -al generar únicamente cosa juzgada formal- de volver a demandar en sede arbitral dentro de los límites de la competencia del tribunal -de ser posible- o accionar la vía ordinaria.

(e) Para la nueva causal de motivación, en caso de ser incluida, recomendamos que la ley deje claro que deberá designarse un nuevo tribunal arbitral que deberá emitir un laudo motivado en mérito de los autos.

\section{Conclusiones}

A lo largo de este trabajo se ha hecho una revisión sobre instituciones contenidas en la LAM que, o bien han nacido obsoletas por la falta de familiaridad del legislador ecuatoriano con el funcionamiento del arbitraje, o bien se han estancado en relación a su dinamismo y consecuente evolución. De esta manera, la LAM presenta un procedimiento ritualista y poco adaptado a las necesidades de agilidad y flexibilidad de quienes prefieren el arbitraje como mecanismo de solución de conflictos. 
Entre los problemas tratados se encuentran:

(i) Los plazos no adecuados para el ejercicio del derecho a la defensa y el otorgamiento de potestades jurisdiccionales a los directores de los centros de arbitraje. Frente a esto, se ha propuesto que el proceso arbitral inicie con una notificación o solicitud de arbitraje, que se extienda el término para la presentación de la contestación a la demanda y, de ser el caso, la reconvención, o que se eliminen de la LAM los plazos para presentar la contestación y reconvención, dejando su determinación a los reglamentos de arbitraje.

(ii) La excesiva rigurosidad exigida para la celebración de convenios arbitrales válidos y la indeterminación de su naturaleza. Al respecto, se ha planteado adaptar sistemáticamente el ordenamiento jurídico a lo dispuesto por la Convención de Nueva York en lo referente al requisito de escrituración del convenio arbitral o adoptar cualquiera de las opciones contenidas en la Ley Modelo CNUDMI sobre Arbitraje Comercial Internacional (2006), que arrojarían mayores luces sobre la naturaleza de la formalidad de escrituración exigida para los convenios arbitrales.

(iii) La noción constitucional y legal de materia transigible como criterio de arbitrabilidad. Sobre esto, se ha propuesto la adopción de una presunción a favor de la arbitrabilidad de las controversias privadas y la eliminación de la noción de transigibilidad como criterio de arbitrabilidad objetiva de las normas constitucionales y legales o, por lo menos, una interpretación que matice su alcance.

(iv) La rigidez del procedimiento arbitral dada por la supletoriedad directa de normas adjetivas ritualistas. Ante este problema, hemos propuesto una fusión del sentido de los artículos 37 y 38 de la LAM para dar prevalencia al acuerdo de las partes, a las reglas dictadas por el tribunal arbitral en atención al caso concreto y a las fuentes 
autocontenidas del sistema arbitral frente a la aplicación de la norma procesal común. Adicionalmente, hemos sugerido la implementación de la celebración de una conferencia para determinar la forma de conducción del procedimiento arbitral que culmine en la suscripción de un acta de misión o similar y la fijación de un calendario procesal.

(v) La inadecuación del sistema de causales de excusa y recusación recogido por la LAM. Hemos considerado que, frente a este inconveniente, que desconoce la naturaleza y particularidades de la institución arbitral, se debe adoptar un estándar objetivo de razonabilidad. Este serviría para establecer si una determinada circunstancia debe ser revelada o si debe ser motivo para que un árbitro se excuse o las partes lo recusen. Además, este criterio de razonabilidad para la revelación de circunstancias que podrían comprometer la independencia e imparcialidad del árbitro, a nuestro criterio, debe mantenerse a lo largo de todo el procedimiento arbitral hasta la emisión del laudo y servirá para que la autoridad que conozca de una potencial recusación, la resuelva.

(vi) La desnaturalización de la justicia cautelar al no ser capaz de proteger la disputa, preservar el status quo del conflicto, asegurar el resultado del laudo ni prevenir una innecesaria agravación del conflicto. Frente a esto, se ha sugerido la implementación de un sistema de arbitraje de emergencia mediante el cual, mediante un trámite expedito, un árbitro designado temporalmente podrá asumir competencia para determinar la procedencia de las medidas cautelares solicitadas.

(vii) La insuficiencia de la regulación de la nulidad de laudos arbitrales. Ante esto, hemos propuesto, con ciertos matices, la inclusión de tres causales de nulidad a ser conocidas también por el presidente de la Corte Provincial correspondiente: (i) inarbitrabilidad de la 
controversia, (ii) incompetencia en razón de la persona y de la voluntad y (iii) falta de motivación del laudo. Además, hemos sugerido la regulación de los efectos de la nulidad los cuales, dependiendo de la causal específica en que se funde, deberán consistir en la retrotracción del procedimiento hasta el momento en que se incurrió en la causal, preservación únicamente de la parte congruente del laudo, nulidad de todo el proceso o conformación de un nuevo tribunal arbitral.

Como se ha visto, las dificultades aquí abordadas demandan una reforma que no es solo conveniente sino imperativa, pues el estado actual de las instituciones procedimentales de la justicia arbitral, además de las dificultades prácticas que comporta para el desenvolvimiento de los procedimientos arbitrales, entorpece la evolución de la academia, que se ha estancado tratando de resolver problemas que, en otros lugares de la región y del mundo, han sido superados mediante un mejor entendimiento de las características esenciales del arbitraje, sus instituciones, su desarrollo, pero, sobre todo, su fundamento. 



\title{
2 E
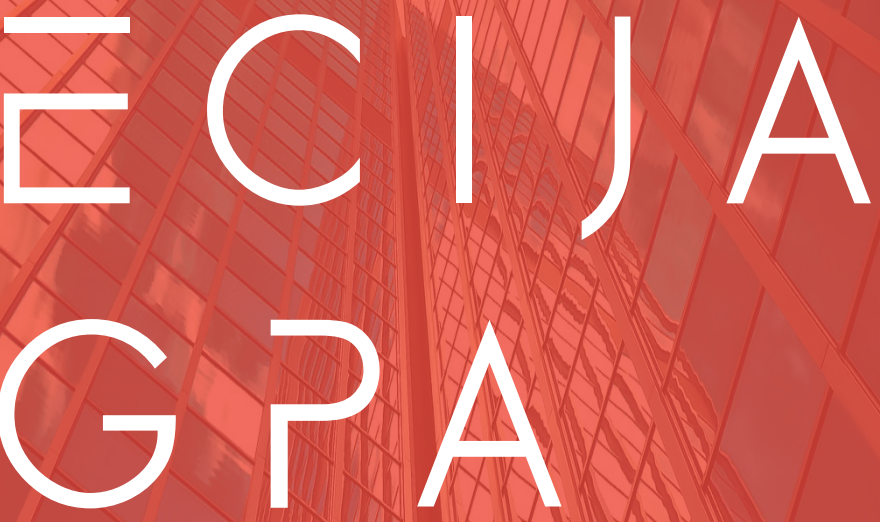 \\ Uno de los mejores despachos legales multidisciplinares e independientes del mercado ecuatoriano
}

\author{
Más de 600 profesionales \\ 26 oficinas a nivel mundial \\ Presencia en 15 países
}

info.ecuador@ecija.com

Av. 12 de Octubre N26-97 y Abraham Lincoln, Ed. Torre 1492, Piso 10 Quito - Ecuador Tel: + (593-2) 2986528/29/30/31
Av. Numa Pompilio Llona $s / \mathrm{h}$, Puerto Santa Ana

Ed. The Point, Piso 8, oficina 806 Guayaquil - Ecuador Tel: (+593 4) 3883007 



$$
\frac{3 . \text { sección }}{\text { Ensayos Libres }}
$$


